\title{
A relação entre Caio Prado Júnior e Celso Furtado
}

\author{
Igor Zanoni Constant Carneiro Leão* \\ Newton Gracia da Silva*
}

\begin{abstract}
RESUMO - Este texto esclarece algumas das contribuições fundamentais de Caio Prado Júnior e Celso Furtado à interpretação do desenvolvimento brasileiro, indicando sua importância nas nossas escolas tão viciadas na leitura de materiais secundários e livros-texto.
\end{abstract}

Palavras-chave: Desenvolvimento. Pensamento econômico brasileiro.

Em nossas faculdades de Economia tão cheias de manuais de utilidade duvidosa, alguns textos clássicos foram preservados para bem dos nossos alunos. Aqui fazemos uma nota sobre alguns livros de Caio Prado Júnior e Celso Furtado, relacionando-os de passagem com outros autores singulares na nossa bagagem intelectual.

História Econômica do Brasil (1945), de Caio Prado Júnior, é um dos textos ainda hoje mais utilizados nas nossas universidades como introdução à formação econômica do país. Seu autor foi um ilustre filho da família Prado, grande expoente da antiga burguesia cafeeira paulista entre o Império e a Primeira República. Entretanto, Caio seguiu rumo bastante diverso, ao optar desde moço pela militância no antigo Partido Comunista do Brasil e criando como analista econômico e político da história e da atualidade brasileira uma versão marxista propriamente original e nacionalista, muito distante dos textos canônicos do PCB, cujo grande expoente era Nelson Werneck Sodré. Caio foi também empresário, criando com Monteiro Lobato a Editora Brasiliense, e eleito deputado por São Paulo nas eleições de 1945. Faleceu em 1990, após longa e incapacitante enfermidade.

Caio pertenceu à geração modernista dos anos trinta, que renovou profundamente a historiografia e a ciência social no Brasil, juntamente com Gilberto Freyre (Casa grande e senæala, 1933) e Sérgio Buarque de Holanda (Raízes do Brasil, 1936), publicando no mesmo período Evolução política do Brasil (1933), obra em que destacava a formação social do país a partir da colonização e da passagem para o período imperial, estudando como nunca fora feito antes a participação da população nas lutas de independência e nos movimentos políticos do século XIX antes da conformação conservadora do nosso federalismo imperial.

\footnotetext{
* Doutor em Economia pela Universidade Estadual de Campinas. É professor do Departamento de Economia da Universidade Federal do Paraná. Endereço eletrônico: igorzaleao@yahoo.com.br.

** Graduando em Economia pela Universidade Federal do Paraná. É bolsista do PET Economia/UFPR. Endereço eletrônico: newton.gracia@gmail.com.
} 
Em 1942 publica sua obra-prima, Formação do Brasil contemporâneo, um dos dez livros considerados mais importantes para ler e compreender o Brasil, no qual destaca a nossa formação colonial. O livro deveria ser seguido por outros dois, que abarcariam respectivamente o Império e a República burguesa, mas essa sequência se dissolveu, restando seu marco inicial e $A$ bistória econômica do Brasil, cujo auge é a passagem para os primórdios da industrialização brasileira, a partir de 1930, com a Revolução de 1930 chefiada por Getúlio Vargas. Este último livro em sua primeira terça parte condensa Formação do Brasil contemporâneo, não apresentando nada teoricamente novo a este. A obra de Caio, aliás, centra-se em poucas grandes ideias repetidas ao longo de sua obra como os grandes motivos que estruturaram e estruturam a história econômica, política e social do país.

A mais importante dessas ideias encontra-se no capítulo inicial de Formação do Brasil contemporâneo, chamado O sentido da colonização. Segundo Caio Prado, o Brasil foi colonizado como peça essencial da estruturação do capitalismo europeu na época mercantilista, como espaço para a produção de mercadorias destinadas a consumo, seja como matérias-primas seja como bens de consumo para a cesta de salário da população trabalhadora na Europa. O Brasil é, pois, um espaço para a extração de bens destinados a mercados e população forâneos, e não para atender às necessidades da população que se formava na colônia e no que viria a ser a nação após a independência.

Em decorrência, a colonização brasileira ocorre por ciclos de produtos de grande aceitação no mercado europeu, como o ciclo do açúcar, do ouro ou da borracha, cada um dos quais pouco significando de construção durável para a formação da nação em lenta gestação. O ciclo do café, já no Império, deixaria algo mais, como o impulso para as primeiras fábricas, basicamente de produtos não duráveis, de tecnologia disponível no mercado e investimento inicial relativamente baixo, e como conformação da classe assalariada no país e impulso para o fim do trabalho escravo e do sistema político imperial. A própria independência vem como esgotamento do período colonial graças à industrialização europeia a partir de 1780 na Inglaterra, inicialmente, e das Revoluções Burguesas naquele continente, destacando-se a Revolução Francesa iniciada em 1789. Estes acontecimentos ensejam a passagem para a independência na medida em que se torna imperativo o fim do estatuto colonial, com a ampliação do espaço brasileiro como mercado consumidor das manufaturas europeias e grande produtor de mercadorias para o crescimento industrial e urbano europeu.

Entretanto, esta passagem é, para o autor, inconclusa, na medida em que a independência política do Brasil mantém um império escravocrata aferrado a valores arcaicos que só seriam superados progressivamente com a República e sua ideologia burguesa. Nesse sentido, 
o caráter colonial da formação econômica e social brasileira se mantém como uma relíquia bárbara, que ainda não fora superada de todo quando o livro é escrito.

$\mathrm{Na}$ verdade, para Caio Prado Júnior, o Brasil ainda irá, avançado em muito o século $\mathrm{XX}$, destacar-se por uma produção basicamente para satisfazer às necessidades de mercados externos, e não da população que vive e trabalha no país. Em grande medida isto ocorre porque o grosso das fábricas instaladas no país é de origem estrangeira, ligadas ao imperialismo dos países do centro econômico mundial. Dessa forma, o pagamento de juros e lucros internacionais obriga a manutenção de um anacrônico sistema neocolonial e a exportação de produtos básicos e matérias-primas para o comércio externo como forma de angariar divisas para estas despesas.

Ao mesmo tempo, este estado de coisas faz com que as características centrais do sistema colonial, como a ausência de soberania política, a desigualdade social e racial, a heterogeneidade social e produtiva, se mantenham como um lastro que é preciso jogar fora. Como Caio Prado Júnior é um grande otimista, esta passagem da produção neocolonial para uma produção e uma estrutura econômica e social nacionais visariam sobretudo o povo brasileiro e conduziriam a maior igualdade social, distribuição de renda, mudança na distribuição de terras baseada na grande propriedade de fundo colonial. Isto porque o imperialismo não tem como manter-se em longo prazo de forma crescente, e inscreveria o país na agenda de uma revolução cujos traços ele esboça em livros como $A$ revolução brasileira (1966).

Este guarda um parentesco com o capítulo de Raízes do Brasil, de Sérgio Buarque, $A$ nossa revolução, que propõe uma transição a um projeto autônomo de desenvolvimento brasileiro, a partir das nossas contradições e de nossa herança colonial, cuja superação se impõe. Assim, em Caio Prado também há uma preocupação imensa com a cultura nacional. O conceito de nação é no autor formado a partir de laços de solidariedade criados por uma cultura comum. Esta é a meta, a consecução da passagem de uma economia colonial para uma economia nacional. Economia, mas também sociabilidade cultural, superação do imperialismo e da dependência.

Quando tomamos outro grande autor, como Celso Furtado, com origem na CEPAL, mas guardando uma forte originalidade que o faz dialogar com o marxismo enquanto valorização do desenvolvimento na plena acepção do termo, e não crescimento econômico mimético e parcial, subordinado aos centros, percebeu a mesma linha de análise de Caio Prado. O que os distingue é mais a familiaridade do paraibano com os termos da linguagem econômica do que sua ética e seus respectivos projetos sociais.

Assim, em outro grande texto felizmente preservado na universidade brasileira como introdução ao estudo da economia do país, Formação econômica do Brasil, Furtado trabalha com o 
conceito de fluxo de renda, próximo ao multiplicador de emprego e renda keynesiano, através do qual examina o impacto de um gasto com o fabrico de bens para exportação na colônia, ou com o investimento induzido pelas exportações, já no século XIX, relacionando-o ao espaço das relações de produção e propriedade.

Por outro lado, Furtado se preocupa, como intelectual e homem público, com a economia política brasileira, o espaço das tensões culturais e políticas entre as classes sociais e a dependência tecnológica, financeira e cultural dos países centrais. Nesse sentido, o conceito de nação em Furtado tem o mesmo sabor que em Caio Prado, e incita uma discussão sobre a cultura material e social/política no país.

Celso Furtado apresenta uma teoria do desenvolvimento, na qual a cultura tem papel central na perpetuação ou ruptura das estruturas econômicas de poder que, ora facilitam, ora restringem à satisfação das "múltiplas necessidades de uma coletividade" - origem do dinamismo que impele uma sociedade ao desenvolvimento (FURTADO, 1969). O autor parte, em alguma medida, do paradigma "centro-periferia" e da "deterioração dos termos de intercâmbio" influenciado pelo ambiente intelectual da CEPAL no decênio de 1950. Contudo, esse referencial analítico serviu mais como base para a compreensão da materialidade econômica da condição subdesenvolvida e do movimento da economia global, do que para o entendimento das formas de sociabilidade que perpetuavam, nessas sociedades nacionais tão heterogêneas e joviais (países com um século e meio de existência formal), as estruturas rígidas de poder em associação com o estrangeiro. Nesse sentido, o referencial cepalino incentivou a formação do pensamento de que o subdesenvolvimento surgiu onde "o novo sistema de divisão internacional do trabalho permitiu que crescesse o produto líquido mediante simples rearranjos no uso da força de trabalho disponível” (FURTADO, 1974). Por outro lado, o autor reconhecia que tratar sob a perspectiva do "processo de acumulação" a chave das relações centro-periferia, o intercâmbio desigual, possibilitado pela precisa conexão entre as classes dirigentes locais e os grupos que controlam a economia internacional "sem ter em conta a forma como o excedente é utilizado na periferia sob o impacto da colonização cultural, é deixar de lado aspectos essenciais do problema" (FURTADO, 1974). Conclusão símile à do marxista Florestan Fernandes, que encontra, sociologicamente, na associação das elites latinas com o grande capital estrangeiro, parte essencial das estruturas de poder que possibilitam a manutenção do capitalismo periférico numa forma tão imbricada e complexa que as típicas categorias de análise do "processo de acumulação" e "imperialismo" não dariam conta do objeto.

$\mathrm{Na}$ interessante obra $\mathrm{O}$ mito do desenvolvimento econômico, Celso Furtado, no auge de sua produção intelectual, dedica um capítulo do livro aos temas que, ao longo da vida, mais lhe cus- 
taram trabalho: Subdesenvolvimento e dependência: as conexões fundamentais. O capítulo é de extremo valor, pois resume todo um complexo pensamento, ainda que em prejuízo dos desdobramentos teóricos e da filosofia social que o envolve. Assim, o autor identifica três origens para o subdesenvolvimento: (a) expansão e difusão do capitalismo industrial inglês e, mais tarde, europeu e americano; (b) o sistema de divisão internacional do trabalho que implica a especialização produtiva dos países em torno de alguns bens (ou setores); (c) o aumento de produtividade do trabalho engendrado pela simples realocação de recursos para obter ganhos de vantagem comparativa (estática) no comércio - ou seja, esses países funcionaram como peças de acumulação primitiva de capital. Quanto à dependência, pode-se afirmar que suas origens são tanto o uso particular do excedente adicional do comércio internacional - no caso latino-americano, esse foi direcionado à mimetização dos padrões estadunidenses de consumo, principalmente, a partir da segunda metade dos anos de 1950 -, quanto a rápida diversificação dos hábitos de consumo da classe dirigente; isso significa que a reprodução se diversifica e estratifica de modo a se enraizar na sociabilidade como algo quase natural. Entretanto, a importância da "dependência" como fenômeno essencialmente cultural está no fato de que a importação de bens materiais traz consigo a reprodução de um estilo de vida e um modo de pensar que fica embutido no "homem de tipo médio", como John Maynard Keynes denominava as pessoas esclarecidas de fora da Academia.

Estabelecido o referencial maior do qual partia Furtado, pode-se delinear os contornos da cultura em relação ao desenvolvimento no pensamento do autor. Nesse sentido, a cultura, para fins de clareza expositiva, tem duas dimensões que se conectam na complexa instituição da dependência: (I) cultura material; (II) cultura social/política. A primeira se refere à particular reprodução, mimética, dos padrões de consumo dos países centrais. A consequência econômica direta dessa era a introdução de uma dualidade tecnológica profunda no aparato produtivo destinada à satisfação do consumo diferenciado (em certos casos, conspícuo) de pequenas elites. A consequência que se deriva é a lógica necessidade de se concentrar renda para fazer frente ao padrão de consumo importado, incompatível com o nível de acumulação de capital vigente à época. Essa consequência pode assumir formas mais sofisticadas, como a inflação e a correção monetária nos anos de 1960 e 70, ou mais rude, como a elevada exploração, via jornadas longas, do fator trabalho nas atividades do setor primário e terciário urbano. A segunda se refere à capacidade autônoma, culturalmente, de um povo utilizar sua criatividade a serviço de um sistema coletivo de decisões visando o desenvolvimento dessa mesma coletividade. Ou seja:

Somente a criatividade política impulsada pela vontade coletiva poderá produzir a superação desse impasse. Ora essa vontade coletiva só poderá surgir 
se se der um reencontro das lideranças políticas com os valores permanentes de nossa cultura, cujas raízes estão na massa da população (FURTADO, 1984, p. 30).

A preservação da autonomia cultural permite, desse modo, "pensar em desenvolvimento a partir de uma visualização dos fins substantivos que desejamos alcançar, e não da lógica dos meios que nos é imposta do exterior" (FURTADO, 1984). A cultura é, portanto, o conjunto de valores essenciais de uma coletividade num determinado tempo. Sua relação com o desenvolvimento torna-se clara à medida que se compreende o fenômeno como um processo ou devir na história. A categoria analítica que faz a conexão precisa entre essas dimensões da cultura no pensamento de Celso Furtado é a análise dos "centros internos de decisão". Isso porque o comportamento econômico de uma sociedade subdesenvolvida é função, em grande medida, das elites que coordenam as principais decisões, a saber, são quatro níveis de decisão: utilização dos bens e serviços disponíveis; utilização dos fatores de produção destinados à expansão da capacidade produtiva; nível decisório das inversões; e o nível do equilíbrio monetário. Nesse sentido, a cultura emerge como parte do sistema econômico nacional que "se caracteriza pela forma como são coordenadas as decisões dos agentes econômicos" (FURTADO, 1969, p. 207).

Nesta etapa de análise do pensamento de Celso Furtado, o Estado surge como locus privilegiado para a orientação dos centros internos de decisão. A explicação para isso, pelo lado político, não é muito clara. Furtado nunca elaborou uma teoria do Estado, mas pelo estudo da história econômica e da macroeconomia de John Maynard Keynes identificou, claramente, que o Estado, pelo monopólio da política monetária, fiscal e cambial, poderia diminuir a intensidade das flutuações na renda e conduzir as inversões para um fim específico (os interesses da coletividade). Outro motivo para a importância do Estado no pensamento de Celso Furtado não vem da academia: o autor acompanhou, pessoalmente, a reconstrução da Europa no pós-guerra e o estabelecimento do conhecido modelo de welfare state - isso fica retratado no livro $A$ fantasia organizada (1985), no qual ele trata de algumas influências que teve. Destarte, em oposição às ideias autoritárias que imperavam no Brasil do Estado Novo, antes mesmo do Manifesto da Cepal $(1949)^{1}$, Furtado já vislumbrava um Estado de orientação democrática, conduzido por técnicos, alinhados ao pensamento coletivo, capazes de programar políticas em prol do bem estar social. O auge deste pensamento é a aplicação (adaptada) das "técnicas de programação" da CEPAL no Brasil: exemplo disso é a Operação Nordeste e a SUDENE - Superintendência para o De-

1 Alguns pensadores consideram a obra de Raúl Prebisch El desarrollo económico de la América Latina y algunos de sus principales problemas um verdadeiro manifesto sobre as relações centro-periferia.

104 
senvolvimento do Nordeste, cujo autor fundou e foi o primeiro superintendente, durante a presidência Kubitschek.

A guisa de conclusão pode-se destacar que as diferenças mais marcantes entre Caio Prado Júnior e Celso Furtado se referem ao significado da industrialização para o desenvolvimento econômico. O historiador paulista via nesse processo, por um lado, um aumento da dependência dos capitais estrangeiros e uma rigidez na capacidade de mudar a orientação da economia de natureza colonial (RICUPERO, 2005). Por outro, compreendia o fenômeno como etapa necessária à superação, tanto do subdesenvolvimento, quanto da sociedade capitalista em formação. O economista paraibano, graduado em Direito, acreditava, pelo contrário, na capacidade transformadora da industrialização, pois essa seria capaz de colocar o país noutro patamar, onde as restrições materiais seriam um empecilho menor à liberação das potencialidades e criatividade do povo brasileiro na construção de sua sociedade. Contudo, isso é uma meia verdade, pois Furtado também era crítico em relação à presença do capital estrangeiro na economia e, mais especificamente, nos centros internos de decisão (em especial, as grandes empresas e o sistema estatal).

\section{REFERÊNCIAS}

COMISSÃO ECONÔMICA PARA A AMÉRICA LATINA E O CARIBE. Relatório econômico de 1945.

FERNANDES, F. A revolução burguesa no Brasil. Rio de Janeiro: Zahar, 1975.

FREYRE, G. Casa grande e senzala. Rio de Janeiro: Record, 1933.

FURTADO, C. Teoria e política do desenvolvimento econômico. São Paulo: Companhia Editora Nacional, 1969.

FURTADO, C. O mito do desenvolvimento econômico. Rio de Janeiro: Paz e Terra, 1974.

FURTADO, C. Cultura e desenvolvimento em época de crise. Rio de Janeiro: Paz e Terra, 1984.

FURTADO, C. A fantasia organizada. Rio de Janeiro: Paz e Terra, 1985.

HOLANDA, S. B. de. Raízes do Brasil. 5. ed. Rio de Janeiro: José Olympio Editora, 1936.

KEYNES, J. A teoria geral do emprego, do juro e da moeda. São Paulo: Atlas, 1982.

PRADO JÚNIOR, C. Evolução política do Brasil. São Paulo: Brasiliense, 1933.

PRADO JÚNIOR, C. Formação do Brasil contemporâneo. São Paulo: Brasiliense, 1942.

PRADO JÚNIOR, C. História econômica do Brasil. São Paulo: Brasiliense, 1945.

PRADO JÚNIOR, C. A revolução brasileira. São Paulo: Brasiliense, 1966.

RICUPERO, B. Celso Furtado e o pensamento social brasileiro. Estudos Avançados, v. 19, n. 53, 2005. Disponível em: <http://www.scielo.br/scielo.php?script=sci_arttext\&pid=S0103$40142005000100024 \& \operatorname{lng}=$ en\&nrm=iso\&tlng=pt $>$. Acesso em: 21/11/2011. 
